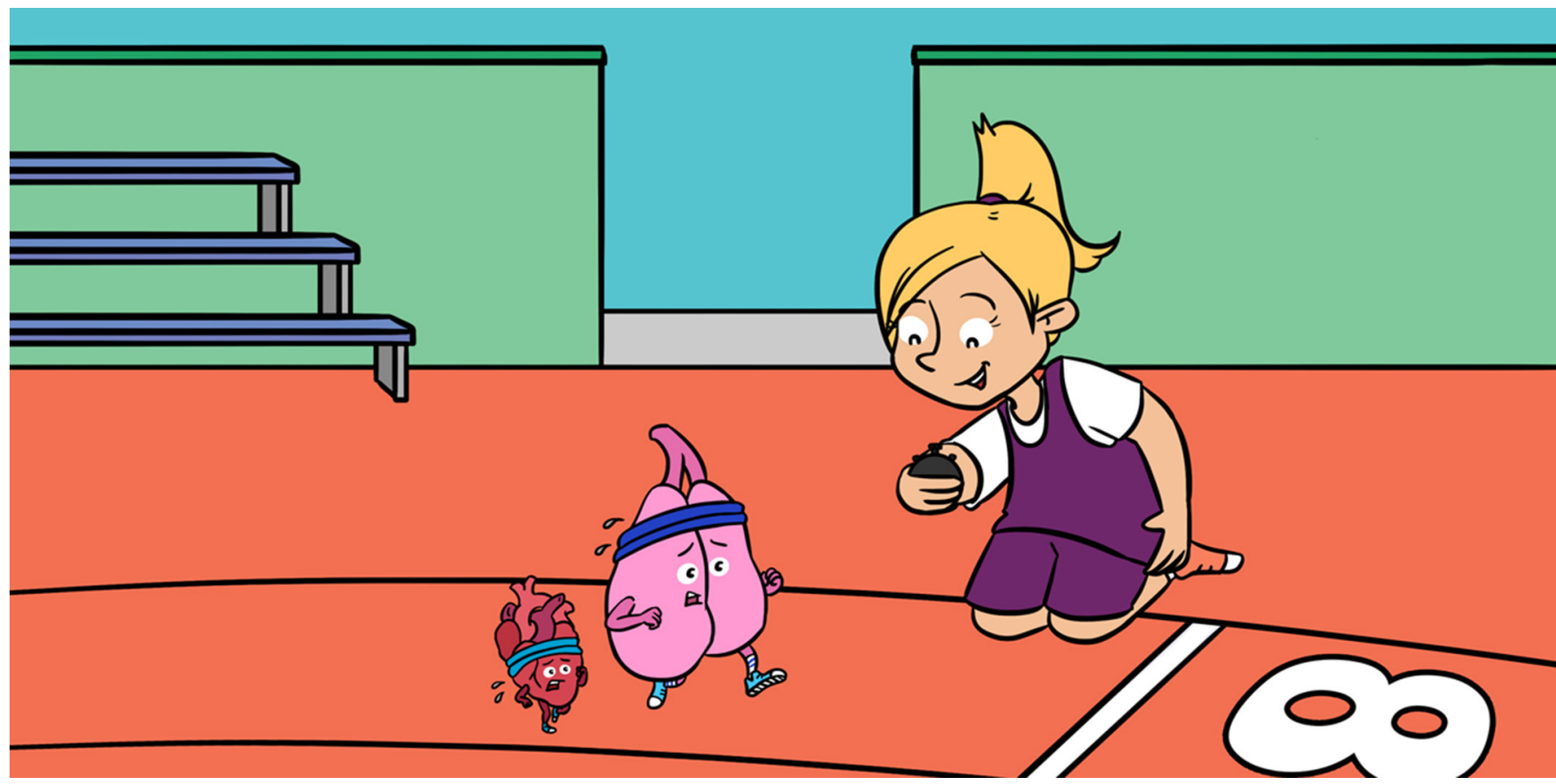

\title{
READY, SET, GO! HOW THE HEART AND LUNGS RESPOND TO EXERCISE
}

\section{Eleanor D. Muise *, Rachel Gordon and Dawn A. Ericson Woods}

Division of Pulmonary Medicine, Boston Children's Hospital and Harvard Medical School, Boston, MA, United States

\section{YOUNG REVIEWERS:}

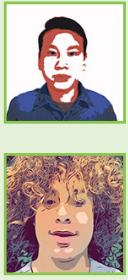

GIGA

AGE: 13

IBRAHIM

AGE: 14

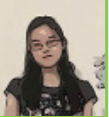

KATHLEEN

AGE: 16
You know when you're racing really fast-so fast that your heart is pounding, and you can't catch your breath? Have you ever wondered why that happens? Imagine you are racing-when you take a deep breath, you breathe in air and your lungs pull oxygen into your blood, then oxygen races to your hungry leg muscles. All that work by your muscles to make energy creates carbon dioxide waste, which travels back to the lungs, and we exhale with a sigh of relief. As you and your muscles work harder to run faster and further, your muscles require more oxygen to make more energy. Over time, with continued exercise, your heart and lungs respond by becoming more efficient at delivering oxygen and making energy. There are even ways to measure how hard your body is working during exercise, and this article will tell you how!

\section{A BREATH OF FRESH AIR IN THE LUNGS}

When we take a breath in, air travels from the nose and mouth, all the way down to the 600 million alveoli, the smallest air sacs in the 
Figure 1

In the tiny air sacs in the lungs, called alveoli, oxygen $\left(\mathrm{O}_{2}\right)$ from the air we breathe attaches to the hemoglobin in red blood cells.

Oxygen-containing blood is then pumped by the heart through the blood vessels to the muscles, where it can be used by mitochondria to make energy from sugar. Mitochondria produce carbon dioxide $\left(\mathrm{CO}_{2}\right)$ as a waste product. When the blood is pumped back to the lungs, the $\mathrm{CO}_{2}$ is exhaled and the cycle begins again (Image credit: Dawn A. Ericson Woods, MD).

\section{HEMOGLOBIN}

A protein in red blood cells that can carry four oxygen molecules.

\section{MYOGLOBIN}

A protein in muscle cells that can take oxygen from hemoglobin.

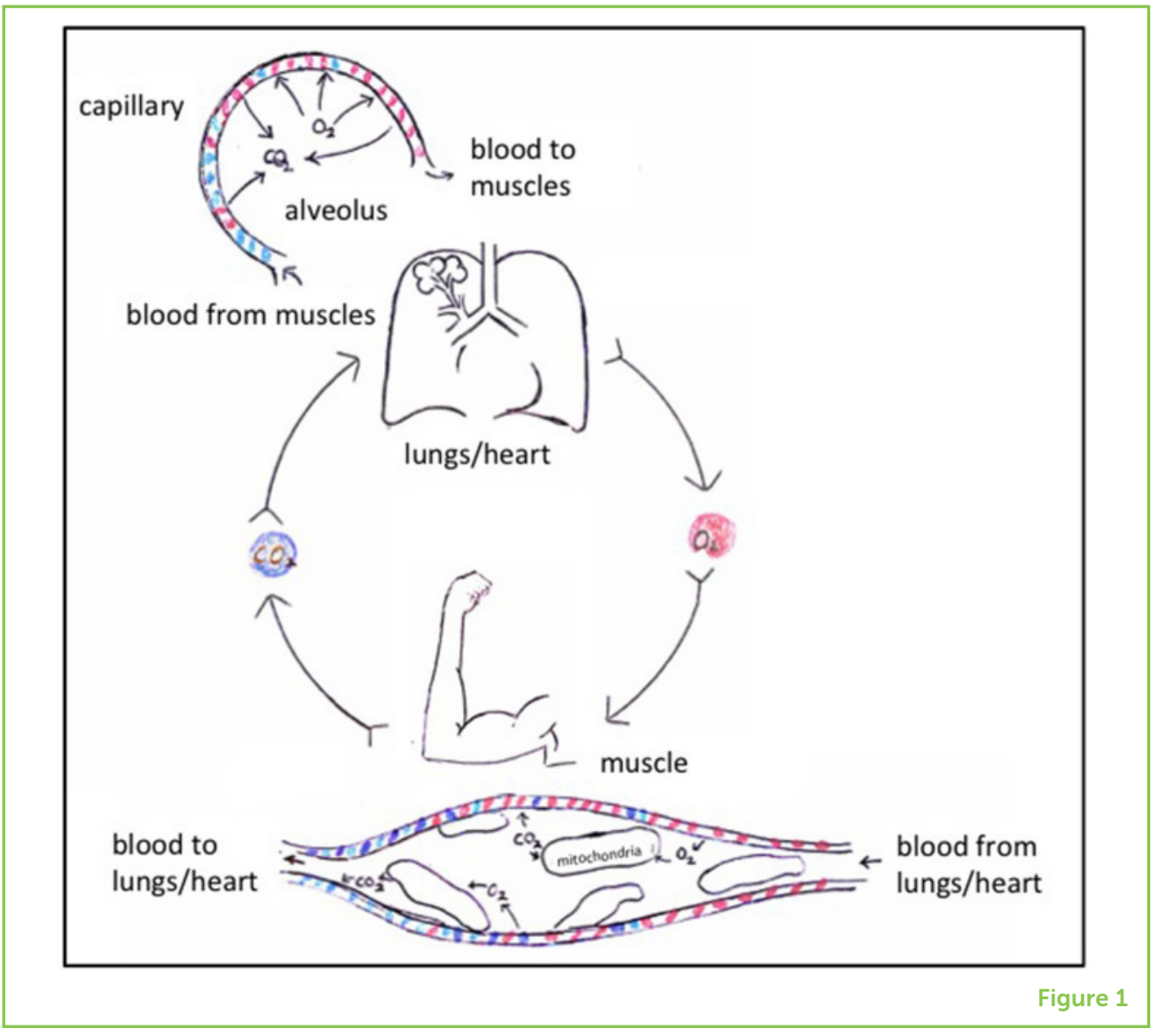

lungs. All the alveoli together have a surface area about the size of a tennis court, which makes the lungs very efficient at pulling out oxygen from air (Figure 1). Hemoglobin, the protein in red blood cells that makes them look red, has a high attraction for oxygen and can carry four oxygen molecules at a time. With oxygen on board, the blood cells are ready to race back to the heart through blood vessels! The heart is responsible for receiving oxygen-rich blood from the lungs and pumping it out to all the organs, like the brain, stomach, and skeletal muscles.

\section{SHOW ME YOUR MUSCLES}

There are over 600 muscles in our bodies. The skeletal muscles are the muscles we can control, and they help us do our daily activities. Muscles need oxygen to make energy efficiently. How do the muscles take oxygen from hemoglobin? When muscles are active, oxygen flows from hemoglobin into muscle cells. Muscle cells have a special protein called myoglobin, which is similar to hemoglobin but only carries one oxygen molecule at a time. Oxygen likes myoglobin even better than hemoglobin. When oxygenated blood arrives in the muscles, hemoglobin unloads oxygen to myoglobin. 
MITOCHONDRIA

A structure within cells that makes energy from glucose (sugar).
CARDIORESPIRATORY SYSTEM

The heart and the lungs, working together.
Myoglobin then transports oxygen to structures called mitochondria inside the muscle cells. Mitochondria are nicknamed the powerhouse of the cell because that is where energy gets made! Each muscle cell has thousands of mitochondria, which take the sugar glucose from the food we eat and break it down, with the help of oxygen, to make energy that cells can use. Every time mitochondria make energy they also make waste in the form of carbon dioxide (Figure 1). If too much carbon dioxide builds up, muscles get sore. Good thing we can send it back to the lungs through the blood vessels and get rid of it by breathing it out!

\section{NOW YOU'RE READY, LET'S RACE}

Let's imagine you go for a jog. As you pick up the pace, you might feel your legs getting a little sore-that might be carbon dioxide building up. Your hard-working muscles demand more oxygen because they need to make more energy to continue to squeeze and contract. Can you think of two ways to get more oxygen into your blood and more carbon dioxide out? You've got it! Breathe faster and take deeper breaths. Can you think of two ways that your heart could pump oxygenated blood to your muscles faster? That is right! Increase how fast the heart is beating or get the heart muscle to squeeze out more blood with each beat. The lungs and heart together are called the cardiorespiratory system, and the increased work performed by the cardiorespiratory system is a normal response to exercise. As more oxygen-poor blood is returned to the lungs along with carbon dioxide from tired muscles, you breathe out carbon dioxide and breathe in air with oxygen that is ready to get picked up by hemoglobin, and the cycle starts again.

The oxygen supplied by the cardiorespiratory system helps muscles break down glucose more efficiently and turn it into energy. Some oxygen normally stays in muscles cells attached to myoglobin, so that muscles can work right away while your heart and lungs work harder during exercise. When you are in shape and your cardiopulmonary system is functioning at peak performance, it means that your muscles have made more mitochondria and that those mitochondria have become more efficient at making energy in the presence of oxygen.

\section{MEASURING YOUR BODY'S RESPONSE TO EXERCISE}

Now that you know a little bit more about how your body responds during exercise, wouldn't it be cool to learn a way to measure how hard your body is working? You're in luck, because there are ways to do just that! Gunnar Borg was a Swedish researcher who developed a rating system for how hard you think you're working during exercise [1]. It's as simple as reporting how you feel when you're exercising. 
Figure 2

The Borg scale is a tool to measure how hard you feel you are working when you exercise, using your rate of perceived exertion (RPE). Adding a zero to each number on the scale approximates your heart rate. The modified RPE was designed for kids with a scale that goes from 1 to 10. At each level of exertion the percent maximum heart rate range is shown, and the last column gives an example of the ranges for a 14 year old.

RATE OF PERCEIVED EXERTION (RPE)

How hard you feel you are working during exercise.

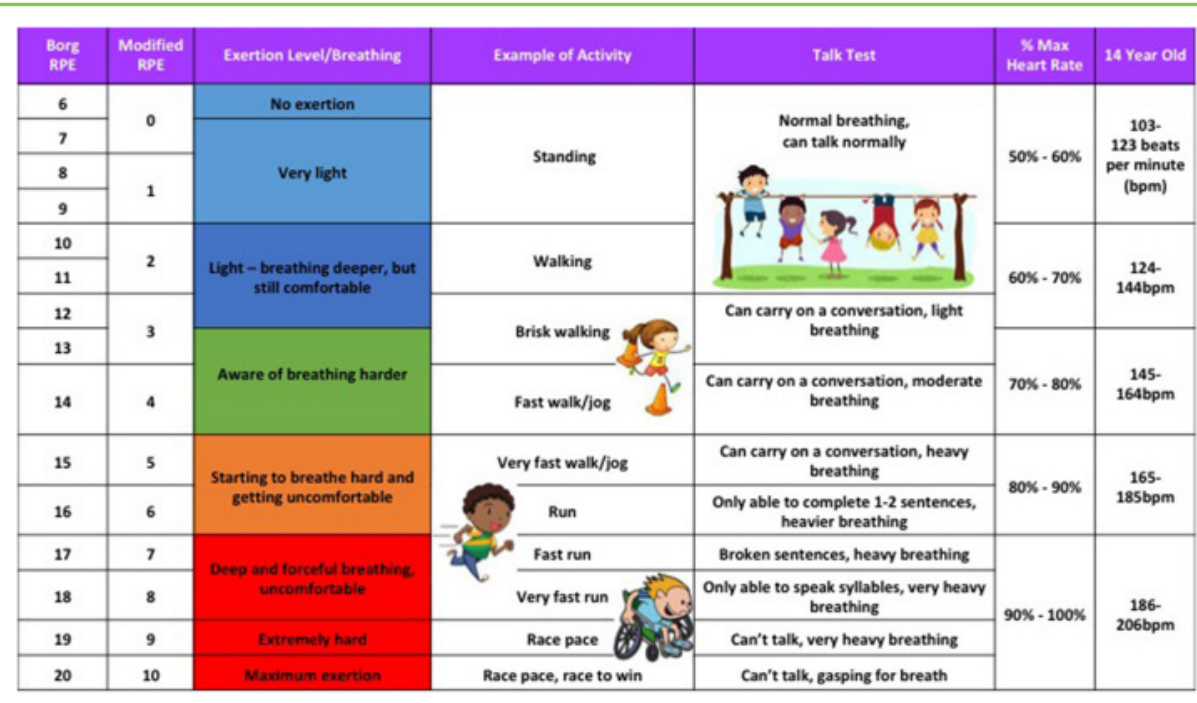

Figure 2

How hard you feel you're working when you exercise is called your rate of perceived exertion (RPE). The Borg scale is based on a range between 6 and 20, with 6 as the least amount of effort and 20 as the most challenging level of effort (Figure 2). If you add a zero to the numbers on the Borg scale, they approximately match your heart rate. So, if your Borg scale score is a 6 , your heart rate is around 60. If your score is 20 , your heart rate is more like 200.

There is a lot of research aimed at evaluating the accuracy of exercise-rating scales like the Borg scale. There are even studies looking at modifications for kids. Scientists compared the effectiveness of the Borg scale and another scale created just for kids. The children's scale went from 1 to 10, with 1 being "very, very easy" to 10 being "so hard I'm going to stop" [2]. The scientists concluded that both the Borg and modified scales worked for kids, and found that kids were just as good at using the scales as adults. The Borg scale is an effective way to measure how hard anyone's body is working!

\section{A PRACTICE RUN}

You can feel for your heart rate by using the first two fingers on the hand you write with and gently placing the pads of your fingers flat against your neck, along your windpipe. Count your pulse for 6 seconds, then multiply by 10, and that's your heart rate in beats per minute. Your maximum heart rate can be estimated by subtracting your age from 220, and that's how many beats per minute you might be able to reach while exercising at your maximum.

Say you are 14 years old. That would make your maximum heart rate 220 minus 14, or 206 beats per minute. To target a good range for exercise, your heart rate should be in the moderate (50-70\% maximum 
heart rate) to vigorous (70-85\% maximum heart rate) ranges. Let's work out the math for $60 \%$, in the middle of the moderate range. Sixty percent of 206 (or $0.6 \times 206$ ) is equal to 124 beats per minute. That's a 12 on the Borg scale, a 3 on the modified Borg scale, and might match up to a brisk walk while you're talking to a friend. Let's do the math for $80 \%$, on the higher end of the vigorous range. Eighty percent of $206(0.8 \times 206)$ is equal to 165 beats per minute. That's a 16 on the Borg scale, a 6 on the modified Borg scale, and lines up with a run during which you can only say a few syllables because you're exercising so hard.

Using these examples, can you calculate your maximum heart rate and your heart rate ranges for each level of effort during exercise? The next time you are exercising, give it a try! Notice how hard you are working, and check the chart to see which color range your level of effort matches. You can double check by measuring your heart rate.

\section{CARDIOPULMONARY EXERCISE TESTING, THE REAL DEAL}

Sometimes lung doctors (pulmonologists), heart doctors (cardiologists), or sports medicine doctors need more detailed information about the body's response to exercise. In our lab, we have a set up to measure everything about the body's response to exercise. Kids exercise on a bike, and we control how hard it is to pedal. We ask them to pedal at the same rate and we make it harder and harder to pedal until they can't pedal anymore. We can measure how much work the body is doing, the amount of oxygen the body uses, the amount of carbon dioxide the body produces, the breathing rate, the volume of every breath, and the heart rate. We can also monitor the heart's electrical activity. With all this information, we can work out whether there are any inefficiencies in the body. One challenge that clinicians and researchers face is that there is no exact normal range of values defined for children who perform exercise testing like there is for adults [3]. Elite athletes like Olympians sometimes use exercise testing to train to be the most efficient, but we can use exercise testing to figure out why kids cannot play their hardest in gym class, too.

If you have trouble when you exercise be sure to talk about it with your parents and your pediatrician who can give you the best advice.

\section{WE'RE AT THE FINISH LINE!}

Let's review the actions of the cardiorespiratory system. When we breathe in air, our lungs pull out oxygen, which is carried in the blood by hemoglobin. Oxygenated blood is pumped through the heart and out into the body, to all the organs, including muscles. Myoglobin in muscle cells picks up oxygen from hemoglobin and delivers it to 
the mitochondria. Mitochondria make energy using oxygen and the glucose from food, and produce carbon dioxide as waste. Finally, carbon dioxide travels back to the lungs and is breathed out, and the cycle repeats. During exercise, the cardiorespiratory system works harder to get more oxygen to muscles.

Understanding and measuring the body's response to exercise are powerful tools. Having an idea of how hard you're exercising can help you reach your fitness goals and, as you improve, it will also help you know when you can make your workouts more challenging. You will know it is time to change things up when your routine seems easy and your heart rate does not go up as much as it did before with the same exercise.

Kids ages 6 through 17 are supposed to get one hour or more of moderate to vigorous physical activity every day, according to the Centers for Disease Control and Prevention [4]. That's around 70-90\% your estimated maximum heart rate, or Borg scale of 14-18 [5]. Listening to your body while exercising and monitoring your body's response to exercise using the Borg score can help you be more aware of how you're feeling physically, too.

Studying how hard the body works during exercise is important because it can help doctors and researchers understand which part of the cardiorespiratory system is limiting exercise, and then help us to target treatments to help kids improve and feel better during exercise. Measuring kids' level of fitness to define normal values is a big project that takes lots of children's hospitals working together. This kind of collaborative effort will also lead to future studies to identify which aspect of kids' lives most predict their level of fitness so that pediatricians and parents can do their best to help kids thrive.

\section{REFERENCES}

1. Borg, G. 1982. Psychological bases of physical exertion. Med Sci Sports Exerc. 14:377-81.

2. Gillach, M. C., Sallis, J. F., Buono, M. J., Patterson, P., and Nader, P. R. 1989. The relationship between perceived exertion and heart rate in children and adults. Pediatr Exerc Sci. 1:360-8.

3. Ashish, N., Bamman, M. M., Cerny, F. J., Cooper, D. M., D'Hemecourt, P., Eisenmann, J. C., et al. 2015. The clinical translation gap in child health exercise research: a call for disruptive innovation. Clin Trans Sci.

8:67-76. doi: 10.1111/cts.12194

4. Centers for Disease Control and Prevention. Youth Physical Activity Guidelines. Available online at: https://www.cdc.gov/healthyschools/physicalactivity/ guidelines.htm

5. Centers for Disease Control and Prevention. Target Heart Rate and Estimated Maximum Heart Rate. Available online at: https://www.cdc.gov/physicalactivity/ basics/measuring/heartrate.htm 
SUBMITTED: 17 March 2021; ACCEPTED: 23 September 2021;

PUBLISHED ONLINE: 26 October 2021.

EDITED BY: Jie Zheng, Boston Children's Hospital, United States

CITATION: Muise ED, Gordon R and Ericson Woods DA (2021) Ready, Set, Go! How the Heart and Lungs Respond to Exercise. Front. Young Minds 9:682141. doi: 10.3389/frym.2021.682141

CONFLICT OF INTEREST: The authors declare that the research was conducted in the absence of any commercial or financial relationships that could be construed as a potential conflict of interest.

COPYRIGHT @ 2021 Muise, Gordon and Ericson Woods. This is an open-access article distributed under the terms of the Creative Commons Attribution License (CC BY). The use, distribution or reproduction in other forums is permitted, provided the original author(s) and the copyright owner(s) are credited and that the original publication in this journal is cited, in accordance with accepted academic practice. No use, distribution or reproduction is permitted which does not comply with these terms.

\section{YOUNG REVIEWERS}

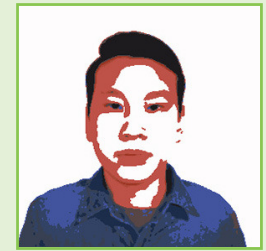

\section{GIGA, AGE: 13}

Giga is a highly motivated young researcher interested in microbiology and mathematics. He is also an excellent soccer player and swimmer at highly competitive levels. Playing piano and guitar is some of his artistic interests. Giga enjoys spending time with his sister and parents when he is not with his friends and teammates.
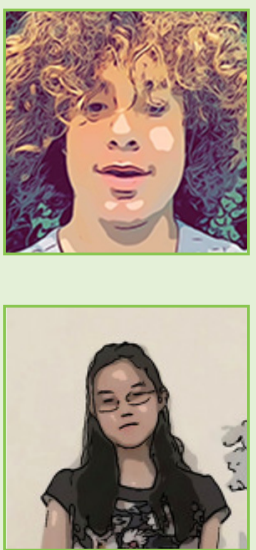

\section{IBRAHIM, AGE: 14}

Hello, my name is Ibrahim. I am 14 years old and live in Boston, Massachusetts. I like mountain biking, skiing, swimming, running, and hiking. I really enjoy learning about science and all the other aspects of science.

\section{KATHLEEN, AGE: 16}

Hello! I am Kathleen, a 16 year old living in Boston. I have always loved science and grew up surrounded by it! In my free time, I like to swim, play piano, and spend time with my family. I like science because it helps explain many things about the world, and because it has the potential to save people's lives! I also enjoy math and chemistry in school.

\section{AUTHORS}

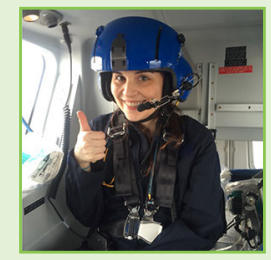

\section{ELEANOR D. MUISE}

I am a pediatric pulmonologist at Boston Children's Hospital in Massachusetts, and I love talking with kids and their parents about healthy breathing. In my research I do procedures and make movies looking into the airways. I try 

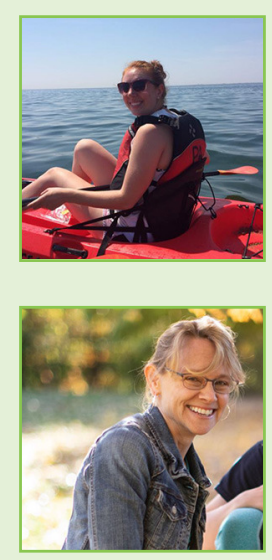

to find out if coughing makes the airways collapse too much. When I am not taking care of kids I love to exercise, bake cookies, and read books. *Eleanor.Muise@childrens.harvard.edu

\section{RACHEL GORDON}

I am a quality improvement data analyst at Boston Children's Hospital. I work behind the scenes to make sure we are providing high quality, safe, and equitable care to our patients. I use specific tools and data to help us achieve this. When I am not working, I enjoy spending time with my family, going for a run, and watching movies.

\section{DAWN A. ERICSON WOODS}

I am a pediatric pulmonologist at Boston Children's Hospital, where I study exercise in children with lung disease to help them be active and healthy. When I am not working, I enjoy biking, reading, sunny days at the beach, and spending time with my family. I can often be found taking my kids to a ninja competition! 